pÿLearning game for training child bicyclists situation awareness

\author{
Lehtonen, Esko
}

2017

Lehtonen , E , Sahlberg , H , Rovamo , E \& Summala , H 2017 , ' Learning game for training pÿchild bicyclists situation awareness ' , Accident Analysis and Prevention, vol. 105 , pp. 72-83 . https://doi.org/10.1016/j.aap.2016.07.036

http://hdl.handle.net/10138/315921

https://doi.org/10.1016/j.aap.2016.07.036

cc_by_nc_nd

acceptedVersion

Downloaded from Helda, University of Helsinki institutional repository.

This is an electronic reprint of the original article.

This reprint may differ from the original in pagination and typographic detail.

Please cite the original version. 


\title{
Learning game for training child bicyclists' situation awareness
}

\author{
Esko Lehtonen ${ }^{\text {a; }}$ Heidi Sahlberga; Emilia Rovamo ${ }^{\text {a }}$ Heikki Summala ${ }^{a}$ \\ ${ }^{\text {a }}$ Traffic Research Unit \\ Institute of Behavioural Sciences \\ University of Helsinki
}

Corresponding author:

Esko Lehtonen

Email: esko.lehtonen@helsinki.fi

Phone: +358294129421

Address: Siltavuorenpenger 1 A, FIN-00014, University of Helsinki, Finland

This is author's accepted manuscript version of the article published as:

Esko Lehtonen, Heidi Sahlberg, Emilia Rovamo, Heikki Summala, Learning game for training child bicyclists' situation awareness, Accident Analysis \& Prevention,

http://dx.doi.org/10.1016/j.aap.2016.07.036.

C 2016. This manuscript version is made available under the CC-BY-NC-ND 4.0 license

http://creativecommons.org/licenses/by-nc-nd/4.0/ 


\begin{abstract}
Encouraging more children to bicycle would produce both environmental and health benefits, but bicycling accidents are a major source of injuries and fatalities among children. One reason for this may be children's less developed hazard perception skills. We assume that children's situation awareness could be trained with a computer based learning game, which should also improve their hazard perception skills. In this paper, we present a prototype for such a game and pilot it with 8-9 year old children.

The game consisted of videos filmed from a bicyclist's perspective. Using a touchscreen, the player's task was to point out targets early enough to gain points. The targets were either overt (other visible road users on a potentially conflicting course) or covert (occlusions, i.e. locations where other road users could suddenly emerge). If a target was missed or identified too late, the video was paused and feedback was given.
\end{abstract}

The game was tested with 49 children from the 2nd grade of primary school (aged 8-9). 31 young adults (aged 22-34) played the game for comparison. The effect of the game on situation awareness was assessed with situation awareness tests in a crossover design. Similar videos were used in the tests as in the game, but instead of pointing out the targets while watching, the video was suddenly masked and participants were asked to locate all targets which had been present just before the masking, choosing among several possible locations. Their performance was analyzed using Signal Detection Theory and answer latencies.

The game decreased answer latency and marginally changed response bias in a less conservative direction for both children and adults, but it did not significantly increase sensitivity for targets. Adults performed better in the tests and in the game, and it was possible to satisfactorily predict group membership based on the scores. Children found it especially difficult to find covert targets. Overall, the described version of the learning game cannot be regarded as an effective tool for situation awareness/hazard perception training, but ways to improve the game are discussed.

\title{
Highlights:
}

A learning game was developed to improve children's situation awareness in bicycling.

The effect of the game was tested with 8-9 year olds with SAGAT like tests.

Signal Detection Theory was used to analyze the results.

The game did not improve sensitivity in the tests, but it decreased answer latency.

Keywords: Hazard perception, Anticipation, Situation awareness, Children, Serious game 


\section{INTRODUCTION}

Bicycling is a popular means of leisure, exercise and transport for children and youth around the world (Macarthur et al., 1998). All forms of active travelling, such as walking and biking to school, are seen as environmentally friendly and an easy and convenient way for children to improve their health (De Hartog et al., 2010; Stewart et al., 2012). However, bicycling related accidents are relatively common. In Finland, bicycling is the form of transport where most (40\%) of children's traffic injuries happen (Liikenneturva, 2015a). In a study conducted by Thompson et al. (1990) in Seattle, Washington, overall bicycle-related injury rates were highest among 10- to 14-year-olds when adjusting the data for miles ridden. Bicyclerelated head injury rates were highest for 5- to 9-year-olds. In Finland, child cyclists aged 10-14 have a risk of injury twice as high as the entire population (Liikenneturva, 2015b). Given child bicyclists' vulnerability due to their still developing physical and cognitive skills, it could be argued that it is important to develop methods to evaluate and improve their situation awareness and hazard perception skills.

\subsection{Situation awareness and hazard perception}

According to Endsley (1995a) situation awareness (SA) is defined as "the perception of elements in the environment within a volume of time and space, the comprehension of their meaning, and the projection of their status in the near future". For acquiring and maintaining SA, Endsley has drawn a careful distinction between three different levels of SA with higher levels depending on the success of lower levels (Wickens, 2008). The first level in SA is to perceive the status and attributes as well as the dynamics of relevant elements in the environment (Endsley, 1995a). At the second level, comprehension of the situation has been formed based on the elements and their relevance for the goals at hand. At the highest level of SA, a prediction of the future status and actions of the elements is present. In other words, SA is more than merely perceiving relevant information in the environment; it involves integration of information and its comprehension relative to the perceiver's goals and anticipation of future events.

Hazard perception (HP) has been defined as the process of detecting, evaluating and responding to dangerous situations in traffic, which have a high probability of leading to accidents or errors (Crundall et al., 2012). HP can be understood as SA for dangerous events in traffic settings, because the ability to use anticipatory cues to predict potential hazards is essential for HP (Horswill \& McKenna, 2004; Crundall, 2016). Therefore, instead of HP, the term hazard anticipation would be also justified (e.g. Pradhan et al., 2009; McDonald et al., 2015).

In HP, not all hazards are equal. A distinction is typically made between latent and acute hazards. Latent hazard means that there are anticipatory cues which can be used to predict the occurrence the hazard (e.g. a ball rolls over the roadway, and after that a child comes running). Using these cues, the hazard can be avoided before it has materialized. In contrast, acute hazards are unpredictable hazards, without any forewarning cues (e.g. child running on the road behind parked cars). Therefore, it has been suggested that acute hazards should not be considered when investigating HP skills (Crundall et al., 2012).

Another distinction for latent hazard can be made according to the type of cues. Latent hazards can be either overt or covert (Vlakveld, 2014). Overt latent hazards are visible road users who start acting dangerously; covert latent hazards are road users who are hidden by an object (e.g. a house, parked cars) but can be on a collision course (Vlakveld, 2014). Corresponding terms according to Crundall et al. (2012) are behavioural prediction hazards and environmental prediction hazards, respectively. Behavioural prediction hazards or overt latent hazards require predicting the behavior of the road user, e.g. a car signalling turning by blinking is likely to turn and thus might end up on a collision course. In environmental prediction hazards or covert latent hazards, prediction cannot be made and the driver needs 
to consider the probability of there being both an object that blocks the view and a road user on a collision course hidden behind the object (Crundall et al., 2012).

HP has typically been investigated using video clips taken from the driver's, motorcyclist's or bicyclist's perspective (Borowsky et al., 2010; Chapman et al., 2002; Crundall et al., 2012; Horswill and McKenna, 2004; Hosking et al., 2010; Lehtonen et al., 2015; Underwood et al., 2013). Each short clip contains one or more hazards and simple press-button responses to these events are often used as the measure of ability (Meyer et al., 2014).

Because good HP skills can result in more time to avoid a collision (Ahopalo et al., 1987; McKenna and Crick, 1994; Pelz and Krupat, 1974), it is not surprising that HP has been indicated to be an important factor in many traffic accidents (Horswill et al., 2015).

Multiple studies have reported differences in HP between inexperienced and experienced drivers and riders: novices respond to hazards more slowly and miss them more often (e.g. Horswill and McKenna, 2004; Hosking et al., 2010; Lehtonen et al., 2015; Underwood et al., 2005; Underwood et al., 2013). Novices also have difficulties identifying potential hazards, and they search and scan the roadway less, tending to focus on the road directly ahead of them compared with experienced drivers and riders (Underwood, 2007; Lehtonen et al., 2014). However, not all of these findings have been consistent, and a number of studies have failed to find the expected differences in HP ability as a function of experience and accident proneness (e.g. Crundall et al., 2002; Sagberg \& Bjørnskau, 2006). Nevertheless, contradictory findings may be due to differences in HP tests (e.g. how hazardous situations are defined), in instructions given to participants, and in the criteria used in selecting novice and experienced drivers/riders (Borowsky et al., 2009; Crundall et al., 2012; Horswill \& McKenna, 2004). It could be argued that a fundamental criterion for a test of HP or SA is that it is able to reflect the differences in the level of HP/SA skill between novice and experienced drivers/riders, or, as in this study, between children and adults.

\subsection{Children in traffic}

Riding a bicycle in traffic is a complicated task of combining motor (e.g. bicycle handling) and cognitive (e.g. attending and responding in traffic) skills or actions at the same time (Ellis, 2014). However, due to children's still developing physical, cognitive and psychosocial abilities, they may be especially vulnerable to traffic dangers (Barton and Morrongiello, 2011; Dye and Bavelier, 2010; Klenberg et al., 2001; Stewart et al., 2012). According to Liikenneturva (2015a) bicycling children are likely to be involved in crashes at intersections, for example where a bike lane and a roadway intersect. Ellis (2014) states that one of the reasons for these accidents is that the child most likely did not conduct a proper search of the traffic environment before crossing. Barton and Morrongiello (2011) furthermore discuss that cognitive processing and attentional demands of crossing a street are various and are not fully developed until the later primary school years. A study conducted by Schaefer et al. (2008) also suggests that children place priority on motor over cognitive task when engaging in both at the same time. An example of such prioritization might be observed in children when they are crossing a busy street intersection on a bicycle. This, of course, has implications for children's risk for injury while bicycling in traffic.

Studies of children's traffic behaviour have focused mostly on road crossing issues, such as finding a safe place to cross or judging safe gaps in traffic (Barton and Morrongiello, 2011; Chihak et al., 2010; Dunbar et al., 2001; Grechkin et al., 2013; Meir et al., 2013; Meyer et al., 2014; Plumert et al., 2004; Plumert et al., 2011). Studies have implied that children tend to have poor pedestrian skills and visual search strategies as well as other perceptual and cognitive limits that can interfere with their capabilities in safe traffic behavior (e.g. Ellis, 2014; Barton and Morrongiello, 2011). However, children's ability to 
anticipate and perceive hazards could protect them from injury and also reduce the possibility of accidents, such as when crossing the road or while riding a bicycle (Meyer et al., 2014). Any rules or skills that children are taught with regard to safety in traffic are only of value if they are able to apply them to a wide variety of contexts after they have recognized a potential danger (Hill et al., 2000).

A study by Oron-Gilad et al. (2011) demonstrated that children under the age of 13 have significantly longer HP latencies as well as lower response rates to some traffic hazards compared with adults. It also showed that adult pedestrians were more sensitive to potential hazards. Hill et al. (2000) also contend that there is evidence that young children are poor at identifying unsafe and risky situations. However, Meir et al. (2013) note that skills required in safe traffic behavior are not completely dependent upon maturation but that experience is an important factor as well. The result in their study indicated that as a pedestrian's age and experience increased, attentiveness towards potential hazards improved and their ability to anticipate events enhanced.

Previous research on children's traffic behaviour has also shown that child cyclists are less competent than adults at road crossing (Chihak et al., 2010; Grechkin et al., 2013; Plumert et al., 2004; Plumert et al., 2011). These studies have demonstrated a significant age difference between children and adults; even though children and adults chose the same size gaps, children ended up having far less time to spare in relation to the approaching car when they crossed the intersection. Relative to adults, children delayed initiation of movement and took longer to reach the roadway. Chihak et al. (2010) point out that there are clear developmental changes in children's abilities; younger children are more likely to make roadcrossing errors than older children.

\subsection{Training}

Hazard perception training programs for young drivers have been successful for improving hazard perception skills, even though their ability to reduce crashes has not yet been confirmed (for review, see McDonald et al., 2015). Training programs for children have often focused on helmet use, traffic knowledge and bicycle handling skills, but have not attempted to improve hazard perception skills (e.g. Richmond et al., 2014). However, McLaughlin and Glang (2010) evaluated a computerized learning program (Bike Smart) regarding the participants' ability to identify hazardous situations. In their study, the program lead to improvement in the hazard discrimination task compared with the control group.

In recent years there has been great interest on serious games, i.e. games designed for educational purposes. Serious games often achieve at least similar levels of performance compared with more traditional educational interventions (Connolly et al. 2012; Girard, Ecalle \& Magnan, 2013). We assume that a video based learning game could train effective visual scanning under restricted time, which is essential for acquisition of situation awareness.

\subsection{Aims of the study}

In this study, we present a prototype of a learning game for training child bicyclists' situation awareness. The learning game was based on video clips filmed from a bicyclist's perspective and the player's task was to point out prespecified targets on the touchscreen as the video was playing. If the player touched a target within its time window, the player got a point. On the other hand, if the player did not point out the target within the time window, no points were awarded and the player was given feedback to pay attention to the target.

There were two kinds of targets, overt and covert (see e.g. Vlakveld, 2014). Overt targets were visible road users, who either were on a conflict course with the cyclist or who could start acting dangerously due to the circumstances, e.g. change their course or speed and end up on a conflict course. Covert targets 
were occlusions or view blockers, like street corners or bus stops, where road user on a conflict course could emerge from behind the occlusion.

The overt and covert targets both had potential to create a hazardous situation and could be classified as latent hazards according to Vlakveld (2014). However, because our aim was to create a game, we wanted to include as many targets as possible in order to make the game more interactive. Therefore, we included also such targets where the situation did not have a 'high probability of leading to accidents or errors' (Crundall et al, 2012), such as when the situation was resolved as unhazardous very early. Therefore, we prefer to use a term target rather than a hazard. We expected that the covert targets would be especially hard for children to detect, because the link between a possible hazard and the stimulus is indirect (cf. Meyer et al. 2014; Meir et al., 2015).

In a pilot study, we evaluated the learning game for its effectiveness with situation awareness tests. The situation awareness tests were also based on video clips. In the tests, the video was stopped and the screen was masked, and 2-3 locations were presented on the screen. The participant's task was to select those locations where there was a target at the moment when the video was stopped and masked. Similar targets were used in the tests as in the game. The SA test used in this study resembled The Situation Awareness Global Assessment Technique (SAGAT) (Endsley, 1995b). However, the queries were restricted to the presence of a relevant element. This was motivated by the desire to make the SA test as simple as possible, and to minimize the working memory load.

We applied Signal Detection Theory (SDT) to analyze the performance in order to investigate the possible effect of response bias (Green \& Swets, 1966; Stanislaw \& Todorov, 1999). Recently, Ventsislavova et al. (2016) presented a hazard perception test for drivers based on the multiple choice approach, and using the SDT, they were able to demonstrate that experienced drivers indeed had better sensitivity to hazards.

Because both the situation awareness test and the learning game were novel, we examined their criterion validity as measures of situation awareness. The different measures of the SA tests and the learning game should be associated with each other if they measure the same construct. Furthermore, the measures should be able to predict the group membership (adults vs. children), if we want to say that they capture something relevant regarding the children's performance.

\section{METHODS}

\subsection{Participants}

The participants in the study formed two groups: a group of children and a group of young adults. There were 49 children, 27 male and 22 female, all 8 years old except one 9-year-old. The children were recruited from the second grade of two primary schools in Helsinki. There were 31 adults, 9 male and 22 female, ages ranging from 22 to 34 . All adults were students at the University of Helsinki. The study was pre-assessed by the ethics review board of the university.

The children were recruited from schools located in areas with bikeways and streets with low traffic density and speed limits in suburban Helsinki, Finland. All participants in the child group except for one had learned to ride a bicycle at the time of the study, and almost all the children reported riding a bicycle at least weekly. The studies were conducted as a part of the children's school day.

All of the participants in the adult group knew how to ride a bicycle. Two groups were recruited for the study depending on recent cycling habits: the frequent cyclists group consisted of 16 participants, and the infrequent cyclists group consisted of 15 participants. 6 participants in the frequent group reported cycling 5-7 times a week, with 10 cycling 3-4 times a week. However, 12 of the experienced participants cycled 
only during the snowless period (roughly from March to November). The participants in the infrequent group reported cycling less than once a month or not at all. (One additional adult participant was measured but was excluded because the participant had cycling habits which did not fall into either of the groups' inclusion criteria.)

The motivation to have both infrequent and frequent bicyclists was to compare the performance as a function of experience. Frequency of bicycling was used as a proxy for cycling experience, because it is easier to report than the lifetime kilometres cycled and more informative than the total years cycled (Lehtonen et al., 2015).

The studies with the adults were conducted at a laboratory at the University of Helsinki, and the participants received a movie ticket or course credit in exchange for their participation. All participants had normal vision or vision that was corrected to normal.

\subsection{Stimuli}

The situation awareness tests and learning game were specifically developed for this study in the Traffic Research Unit at the University of Helsinki. Both the SA tests and learning game were based on videos from Helsinki during spring and summer 2014, filmed from a cyclist's perspective by attaching a camera (GoPro Hero HD1) onto the head tube of a bicycle, approximately at the height of $90 \mathrm{~cm}$. The field of view of the camera was 170 degrees.

The videos were filmed entirely during a snowless period with clear weather. In the first phase, multiple video clips were extracted from the footage based on the judgement of the cyclist who rode the cycle with the camera. The video clips were mostly from bikeways, that is, parts of the pavement reserved for cyclists or separate bike paths. Some clips from low traffic streets were also selected. The targets were identified by the research group based on the target criteria.

The targets were defined based on their potential to cause conflict. Other road users were selected as overt targets if they were on an intersecting course with the bicyclists, or if they could potentially turn to the trajectory of the bicyclists (see Figure 1). For covert targets, it was required that somebody could suddenly emerge behind them. Only few of the situations resulted in a conflict. This was intentional, because we wanted to avoid showing examples of careless or risky traffic behaviour.

In the learning game, each target had a time window when it could be registered. The start point was defined as the point when the targets become visible, and the endpoint was the time when either of the road users started an evasive action or when the situation resolved as non-hazardous (e.g. the other road user had passed the trajectory). Within the time window, the coordinates of the moving target (e.g. a moving pedestrian) were continuously determined, providing a sensitive field that covered the target. In the SA tests, the coordinates for selected targets were only determined at a single time point, i.e. when the video clip was masked.

Finally, a subset of video clips was selected by the research group for the study. The order of the video clips was selected at random for both the SA tests and the learning game, but was the same for all participants. 


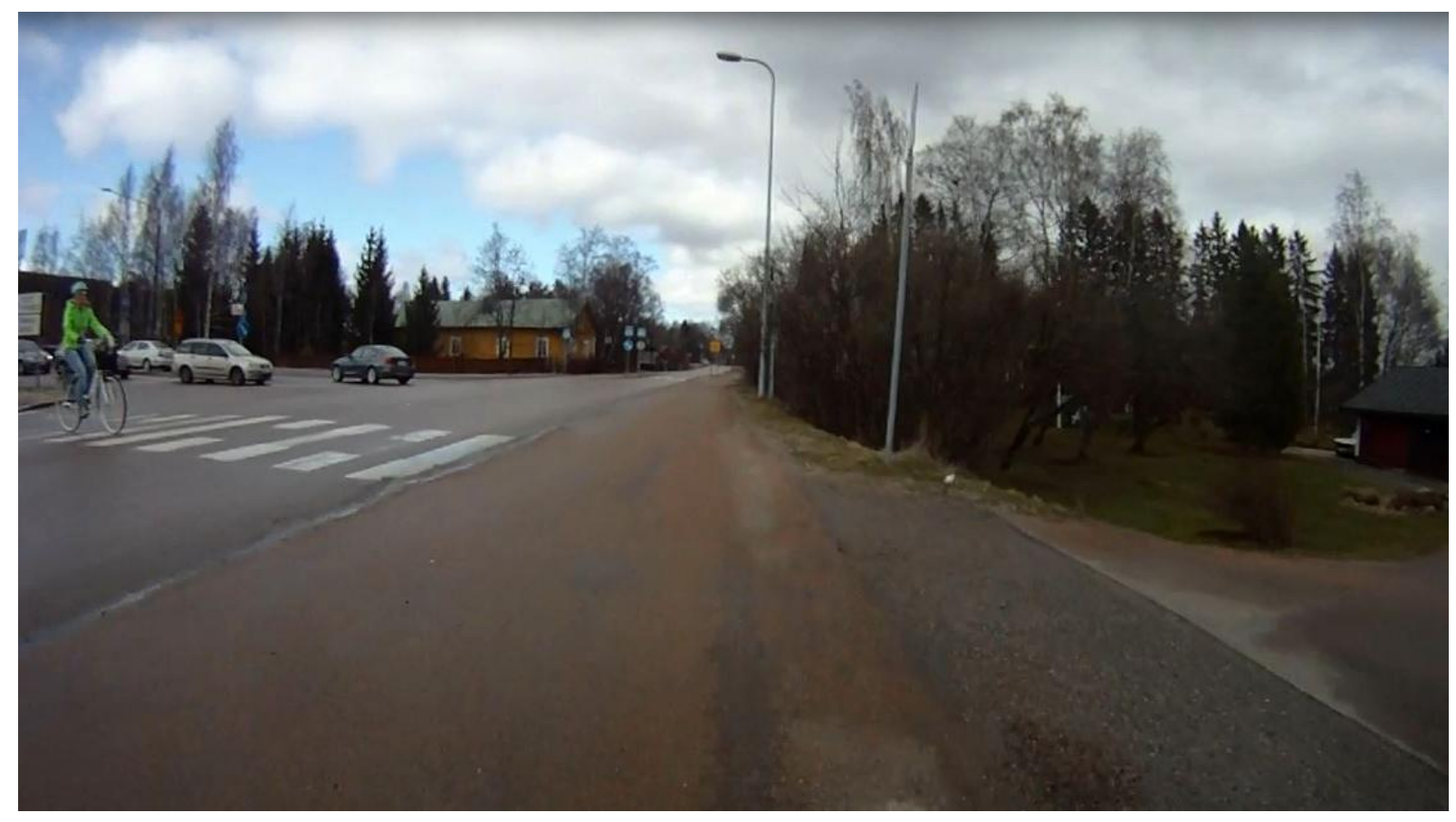

Figure 1. The cyclist at the left is a target that one should spot to avoid a possible collision.

\subsection{Situation awareness tests}

Both the SA tests and the learning game were programmed with Javascript and HTML5 to be playable in a web-browser. The SA tests consisted of 8 video clips, each 5-26 s long (mean $11 \mathrm{~s}$ ). The participant was shown a clip and asked to look for aforementioned targets. At a predetermined point, the video stopped and the screen was masked, and 2-3 rectangles appeared on the screen. The participant's task was to select all the rectangles that contained a target. In each clip, a target could appear in all, some, or none of the rectangles. When the participant clicked on the rectangles, they turned green (see Figure 2), and when the participant thought he/she had chosen the right rectangles, he/she was asked to press 'Next'. The participants were not told whether they selected correctly. The participants completed three SA tests with eight video clips each, i.e. 24 video clips in total. In addition to this, three video clips were used for instruction and practice at the beginning. In the three tests, there were 59 rectangles in total and 35 rectangles had a target behind them.

The SA test used in this study resembled The Situation Awareness Global Assessment Technique (SAGAT) (Endsley, 1995b). However, the queries were restricted to the presence of a relevant element. This was motivated by the desire to make the SA test as simple as possible, and to minimize the working memory load. 


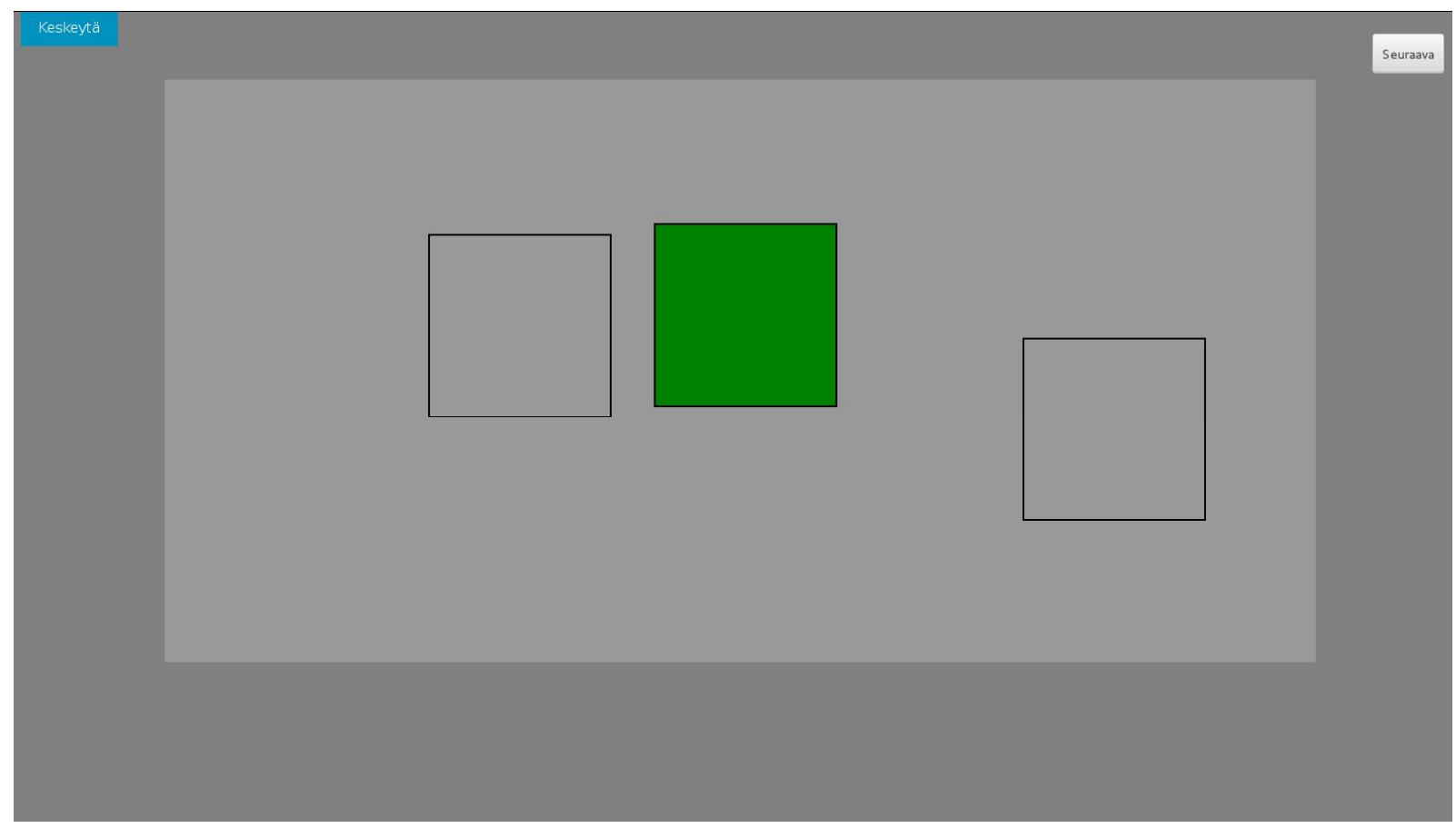

Figure 2. A screenshot from the SA test when the video clip has stopped and the participant has chosen the rectangle in the middle, indicating that there was a target behind it in the video.

\subsection{Learning game}

The learning game consisted of 40 video clips that were 6-72 s long (mean $20.1 \mathrm{~s}$, median $17 \mathrm{~s}$, mode 19 s) and the total duration of the game was approximately $20 \mathrm{~min}$. Before the game, three clips were used for instruction and practice. The participants were asked to point out targets by touching the touchscreen as the video was playing, as soon as they saw them. When hitting a target, the video did not stop, but a green circle appeared around the target along with a sound (see Figure 3a). If the participant touched the screen at a point where there was no target, a little grey circle appeared at the point where the screen was touched. However, if the participant missed a target, the video was stopped along with a warning sound, and a red highlighting appeared around the target (Figure $3 b$ ). The video continued when the participant clicked the highlighted target. Half of the children played with a slightly modified setup where no highlighting appeared; after the warning sound and the video stopping, they had to search for the target themselves. Since there were no differences in performance between the two setups, we chose to have the adults play with just the highlighting setup.

Between the clips the video stopped, and the participant had to touch the screen to continue to the next video, which gave the participant a little pause between the clips. 


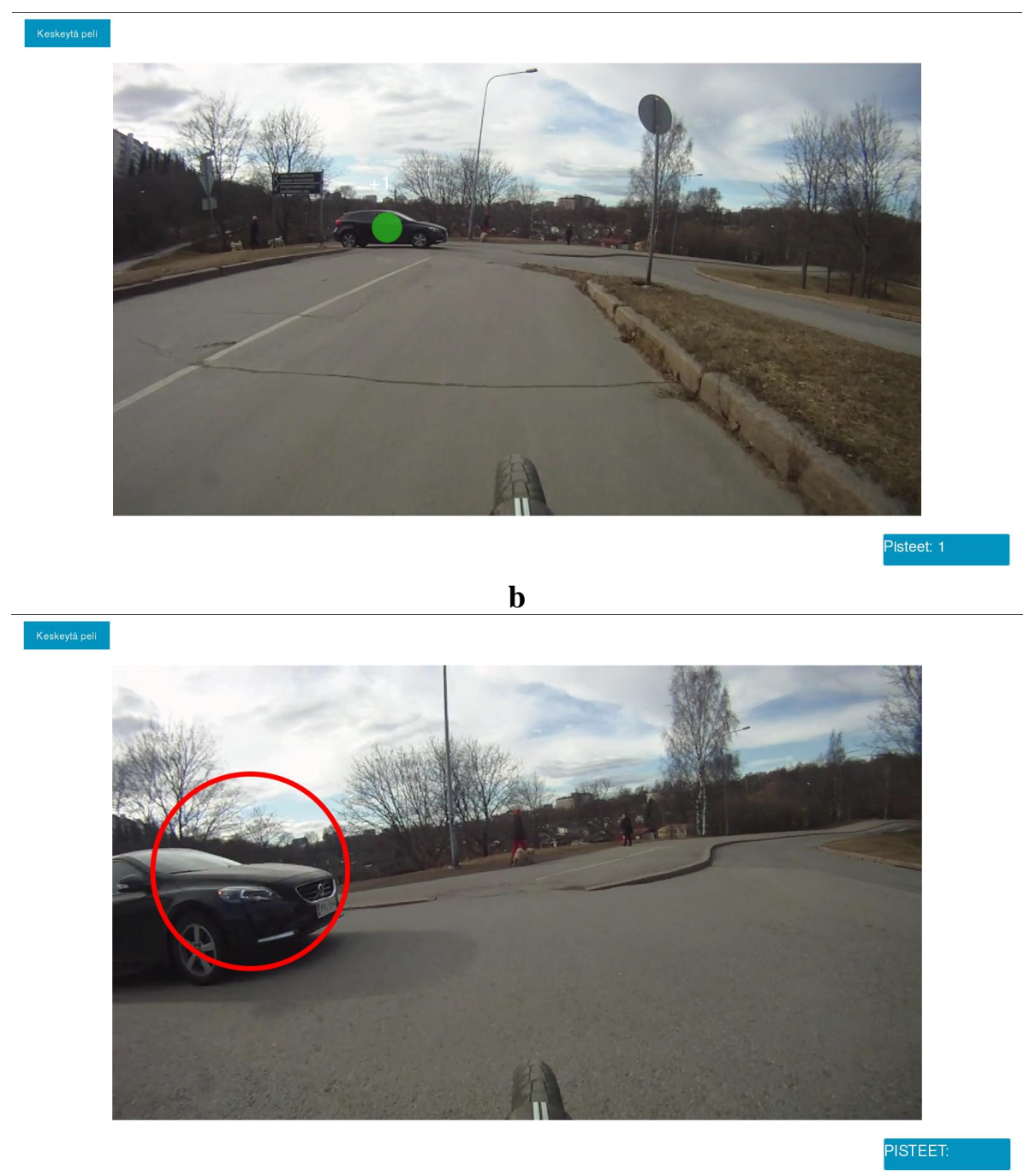

Figure 3. a) A screenshot from the game where the participant has hit a target. b) A screenshot from the game where the participant has missed a target and it has been highlighted.

\subsection{Design}

We used a crossover/switching replications design to investigate the effect of the learning game (Table 1). All participants performed three SA tests in the same order, but half of the participants played the learning game after the first test, and half after the second test. The design is useful for detecting the effect of intervention, and it also allowed all the children to play the game.

After the first test, half of the participants in both adult and child groups started playing the learning game, while the other half completed the second SA test. The first group then completed their remaining two SA tests as the second group completed their last SA test after the game (see Table 1). 
Table 1. The order of the SA tests 1-3 and the learning game in the different groups. The three SA tests are denoted as 1 st, 2 nd and 3 rd.

$\begin{array}{llllll}\text { Age group } & \text { Game position } & \text { Step 1 } & \text { Step 2 } & \text { Step 3 } & \text { Step 4 } \\ \text { Adults } & 1-2 & & & & \\ \text { Children } & 1-2 & 1 \mathrm{st} & \text { Game } & \text { 2nd } & \text { 3rd } \\ \text { Adults } & 2-3 & 1 \mathrm{st} & \text { Game } & \text { 2nd } & \text { 3rd } \\ \text { Children } & 2-3 & 1 \mathrm{st} & \text { 2nd } & \text { Game } & \text { 3rd } \\ \end{array}$

\subsection{Feedback regarding the learning game}

The children were asked three questions to collect feedback regarding the learning game. The questions and their scales were:

1. How fun was the game? very fun - fun - boring - very boring - do not know

2. How easy was the game? very easy - easy - difficult - very difficult - do not know

3. Would you play the game if you had it at home? yes - maybe - no

\subsection{Procedure}

The study was carried out in a laboratory at the University of Helsinki for the adults, and for the children at their school in a separate room reserved for the study. The study was conducted using a Dell Latitude E6400 laptop connected to a 23" Acer T232HL touchscreen with 1930x1080 resolution. The video clips were shown in the middle of the screen on a $41.5 \times 23 \mathrm{~cm}$ large area in the learning game, and respectively on a $40.5 \times 20.5 \mathrm{~cm}$ large area in the situation awareness tests. The inbuilt speakers of the touchscreen were used for audio.

Before the study, the participants were shown a short tutorial video on what to look for in the videos. The tutorial video contained both text and audio narration to make sure that even the youngest participants ( 8 years) would understand everything. After the tutorial and instructions, all participants completed three training clips, and then proceeded to complete the SA tests and the learning game according to the design (see 2.5.)

After the study, feedback regarding the game and background information on participants' cycling experience were collected. The children were interviewed, and the adults were asked to fill in a questionnaire.

\subsection{Measures and statistical analysis}

All the responses in the SA tests were yes or no (selected or not selected), and the answers were either correct or incorrect depending on the presence of a target at the location. This kind of data can be analyzed using Signal Detection Theory (SDT) (Green \& Swets, 1966; Stanislaw \& Todorov, 1999). In SDT, it is assumed that for every yes or no answer, the respondent forms a continuous estimate for how clearly the stimulus is a signal. This estimate is called a decision variable. In the current SA test, this could be characterized as participants' estimate for the presence of a target in the location of the rectangle. If the decision variable is higher than the selected criterion, the participant answers yes (selects the rectangle). When there was a target, a yes answer is a hit, and when there is no target, it is a false alarm. 
The key insight of the SDT is that decision variable values for noise (no target) and signal (target) trials form two distributions, which typically overlap. When there is overlap, it is not possible to answer correctly every time. Two measures can be used to characterize the respondents. Sensitivity describes how well a respondent can distinguish between the signal and the noise, that is, how far the peaks of the two signal and noise distributions are. Response bias describes how much another of the responses are favored.

We use $d^{\prime}$ (d-prime) to measure the sensitivity (Stanislaw \& Todorov, 1999, Equation 1), and $c$ to describe the response bias (Stanislaw \& Todorov, 1999, Equation 7). $d$ ' measures the distance between the signal and the noise distributions. Higher values of $d$ ' indicate better performance. $c$ is the distance between the criterion and the neutral point, where neither response is favored. Thus, negative values mean a bias to respond yes, and positive mean a bias to respond no. Because the calculation does not allow zero false alarm rates, they were replaced by $0.5 / \mathrm{N}$, where the $\mathrm{N}$ was the number of rectangles used in the calculation (see p. 144, Stanislaw \& Todorov, 1999).

In addition to the SDT measures, we also calculated the answer latency for SA tests. Answer latency was defined as the time between the masking of the video and the last answer given in the query. In case there were any unselected rectangles in the query, the pressing of the 'Next' button was used as the time of the last answer. Answer latencies were normalized using a base 10 logarithm because the values were positively skewed (toward long latencies). All the analyses were done with the logarithmized scale and only transformed back for the presentation of the results. The data from the first three training clips were always excluded.

For the learning game, two measures were calculated. Hit rate was calculated as the percentage of targets which the participant had indicated early enough. This required that the participant had touched the dynamically selected area over the target at least once within the selected time window. Time margin was calculated for all the hit targets as the percentage of time window, which was left at the time of the first touch.

For data analysis we primarily used repeated measures ANOVA performed with the R package ez (Lawrence, 2015). Contrast analysis was performed using the R package lsmeans (Russell, 2015). The significance level was set to $\mathrm{p}<.05$. 


\section{RESULTS}

In the results, we will first investigate the effect of the learning game. Then, we will compare the performance of children with that of adults. Finally, we will investigate the criterion validity of the measures used.

We had both infrequent and frequent cyclist as adult participants. As can be seen from Table 2, there was no consistent or significant difference between the two adult groups Therefore, the infrequent and frequent cyclists were collapsed into a single group for later analysis.

Table 2. Comparison of infrequent and frequent adult and child cyclists regarding the percentage of targets hit, the percentage of false alarms, and answer latencies in the three SA tests (1st, 2nd, 3rd). Means and standard deviations in parentheses for each test. The answer latencies are $\log _{10}$ transformed values.

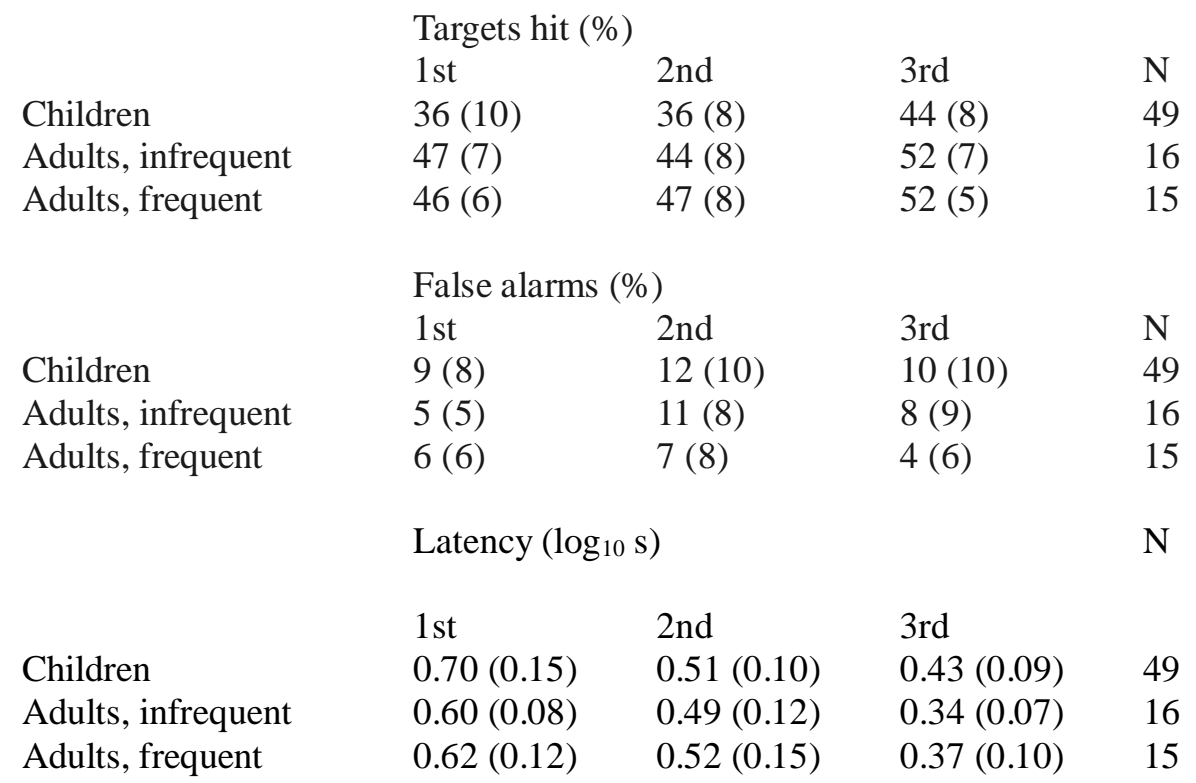




\subsection{The effect of the learning game}

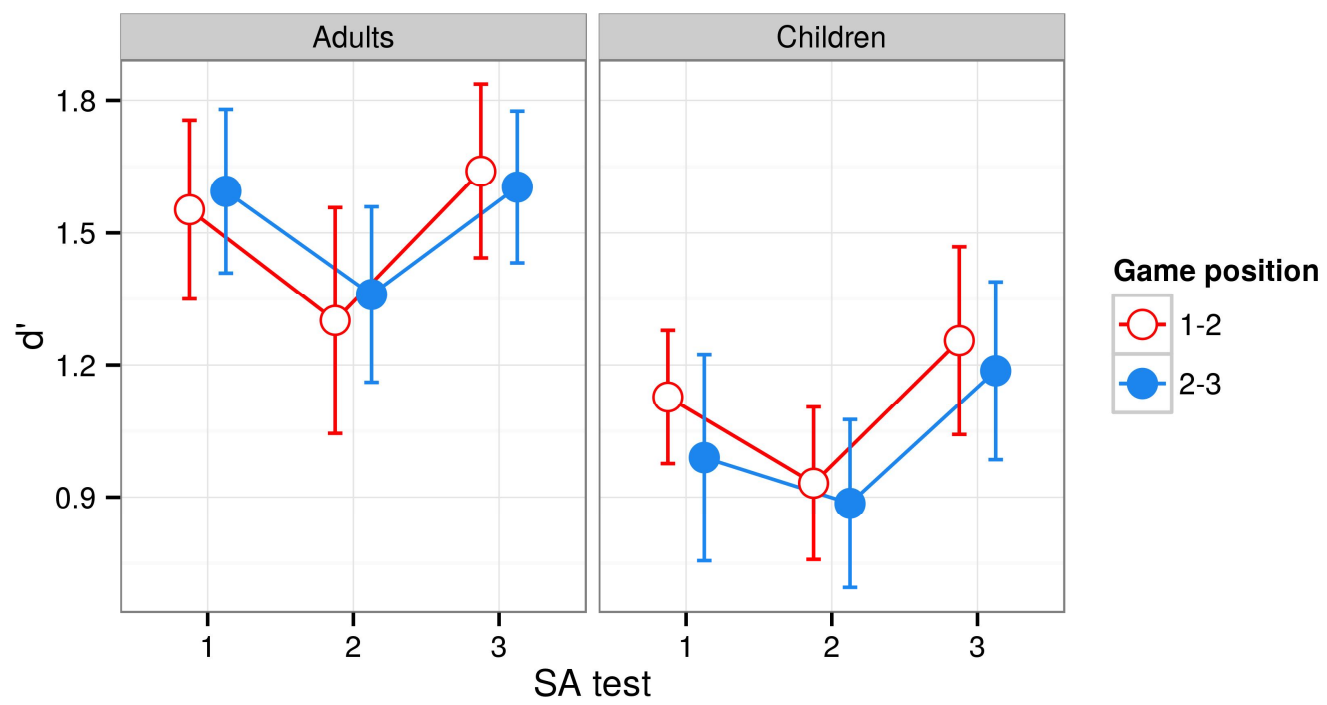

Fig 4. Average sensitivity $d^{\prime}$ in the SA tests with $95 \%$ confidence intervals, adults on the left, and children on the right. The group that played the learning game between SA tests 1 and 2 is indicated with open red circles, the other with filled blue circles. Higher values indicate better performance.

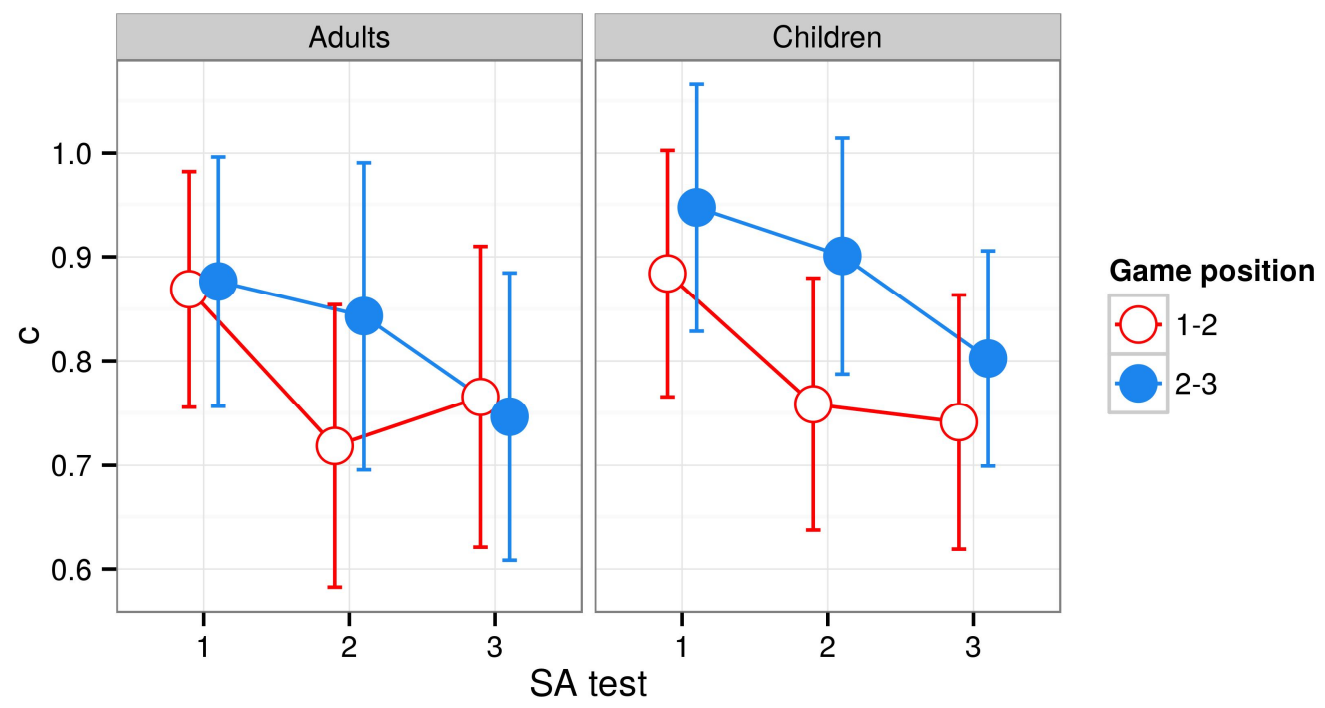

Fig. 5. Average response bias $c$ in the SA tests with $95 \%$ confidence intervals, with adults on the left and children on the right. The group that played the learning game between SA tests 1 and 2 is indicated with open red circles, the other with filled blue circles. Higher values indicate more conservative selection of the rectangles. 

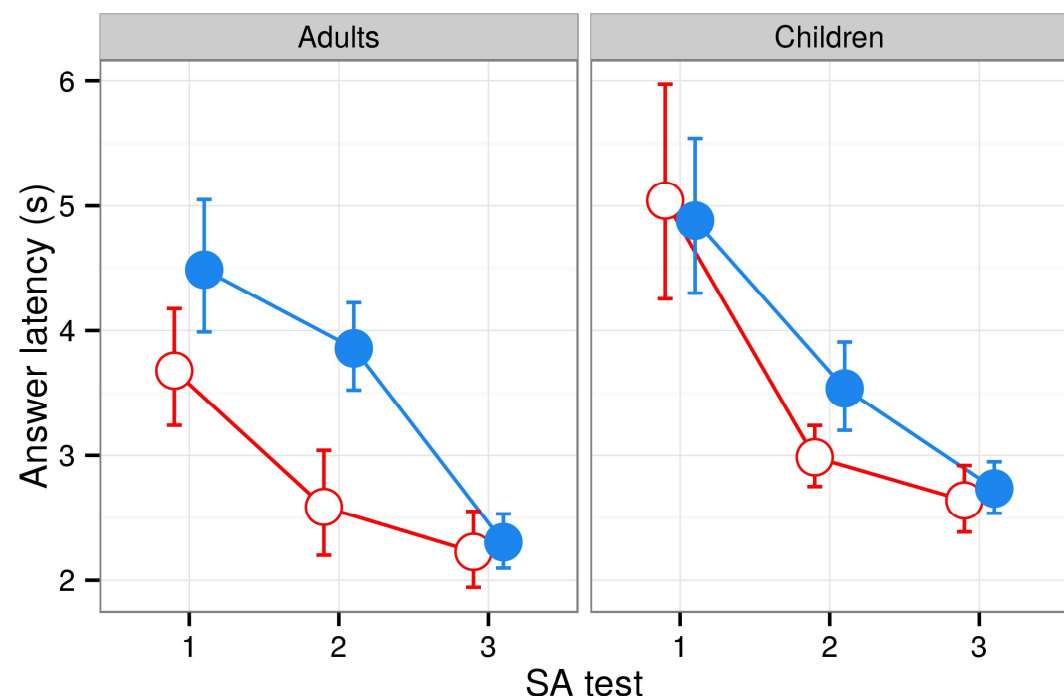

\section{Game position}

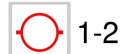

$2-3$

Figure 6. Average answer latencies (s) in the SA tests with $95 \%$ confidence intervals, adults on the left, and children on the right. The group that played the learning game between SA tests 1 and 2 is indicated with open red circles, the other with filled blue circles. In the figure, $\log 10$ transformed values are back-transformed to seconds.

We tested the effect of the learning game using the measures of sensitivity d', response bias c, and answer latency. The answer latencies in seconds were first normalized with $\log _{10}$ transformation because the distribution was skewed to the right (toward long latencies). Half of the participants played the game between the first and the second SA tests (game position 1-2), and half between the second and the third (game position 2-3). Thus, the effect of the learning game should show as a significant interaction of game position and SA test (1st, 2nd, 3rd).

Maucly's test indicated that the assumption of sphericity had been violated with $d$ ' and answer latency ( $p$ $<.05)$, therefore Greenhouse-Geisser corrected tests are reported $(\varepsilon=.90$ and $\varepsilon=.88$, respectively). The learning game had no statistically significant effect on sensitivity $d$ ' (Figure 4$), F(1.80,136.80)=0.15, p$ $=.84$, but it did have a marginally significant decreasing effect on the response bias $c$ (Figure 5), $F(2$, $152)=3.05, p=.05$, generalized eta ${ }^{2}=.01$. Contrasts indicated a significant difference between game positions in the 2nd test, $M=-0.13, S E=0.06, t(119.78)=-2.18, p=.03$, but no significant difference in 1 st and 3rd SA tests, $p>.10$. It should be noted that even though the learning game made responses less conservative, $c$ remained well above 0 even after playing the game, indicating that overall, participants were biased towards not selecting a rectangle. The learning game significantly decreased the answer latency (Figure 6), $F(1.76,133.76)=8.83, p<.001$, generalized eta $^{2}=.04$. Similarly to the response bias, the contrasts indicated a significant difference between the game positions groups on the 2nd SA test only, $M=0.12, S E=0.03, t(166.08)=4.85, p<.001$.

Expectedly, adults had a higher sensitivity $d^{\prime}, F(1,76)=37.84, p<.001$, generalized eta ${ }^{2}=.21$ (adults 1.45 , $95 \%$ CI $[1.36,1.56]$, children 1.01, $95 \%$ CI $[0.91,1.11])$, and shorter answer latency than children, $F(1,76)=8.81, p<.01$, generalized eta ${ }^{2}=.07$ (adults $3.11 \mathrm{~s}, 95 \%$ CI $[2.92,3.31]$, children $3.56 \mathrm{~s}, 95 \%$ CI $[3.34,3.80])$ However, adults and children did not have a statistically significant difference in the 
response bias $c, F(1,76)=0.44, p=.51$. There were no significant interactions between the age group and other factors, indicating that the effect of the game was comparable for adults and children.

SA test (1st, 2nd, 3rd) had a significant effect on all the measures $(p<.05)$. Due to the design, changes in sensitivity can be attributed to the observation that the SA tests were not of equal difficulty (Figure 4). For response bias and especially for answer latency, the change from the first to the third SA test may reflect a true learning effect over the tests.

\subsection{Hit rate and time margins in the game}

We also investigated the performance of children and adults in the learning game using hit rate and time margin (i.e. how much there was left in the time window at the moment of the first hit). Similarly to the SA tests, the infrequent and frequent cycling adults were not notably different regarding the learning game measures (Table 3). For later analysis they were collapsed to a single group.

Adults had a higher hit rate in the game than children, Welch two sample t-test $t(64.42)=9.04, p<.001$, $M=92, S D=4$ vs. $M=78, S D=10$, Cohen's $d=2.25$. Adults also had a larger time margin at the moment of a hit than children, Welch two sample t-test $t(78)=5.89, p<.001, M=63, S D=6$ vs. $M=52$, $S D=10$, Cohen's $d=1.33$.

Table 3. Comparison of children and adult cyclists regarding the percentage of correct answers and time margin in the learning game. The time margin includes only the cases where a target was hit and it was calculated as the percentage of window left at the moment of first hit. The standard deviation is indicated within parentheses after each value.

$\begin{array}{llcc}\text { Group } & \text { Hit rate }(\%) & \text { Time margin }(\%) & \mathrm{N} \\ \text { Children } & 78(10) & 52(10) & 49 \\ \text { Adults, infrequent } & 92(4) & 61(8) & 16 \\ \text { Adults, frequent } & 93(3) & 64(4) & 15\end{array}$

\subsection{Performance as a function of target type}

SA tests and the learning game had both overt and covert targets. We calculated the percentage of correct hits for both target types. The target types were compared in an age group $\mathrm{x}$ target type repeated measures ANOVA in order to investigate if children found the covert targets more difficult than adults. The SA tests were first collapsed.

Significant interactions of age group (adult or children) and target type (overt or covert) indicated that children identified covert targets markedly worse than overt targets, both in terms of percentage of the correctly selected targets in the SA tests (Figure 7), $F(1,78)=10.52, p<.01$, generalized eta ${ }^{2}=.04$, and in the percentage of hit targets in the learning game (Figure 8 ), $F(1,78)=49.47, p<0.001$, generalized eta ${ }^{2}$ $=.13$.

The time margin in the learning game was not tested because the percentage of hit covert targets was low. Consequently, the average time margin would be based only on a few observations. 


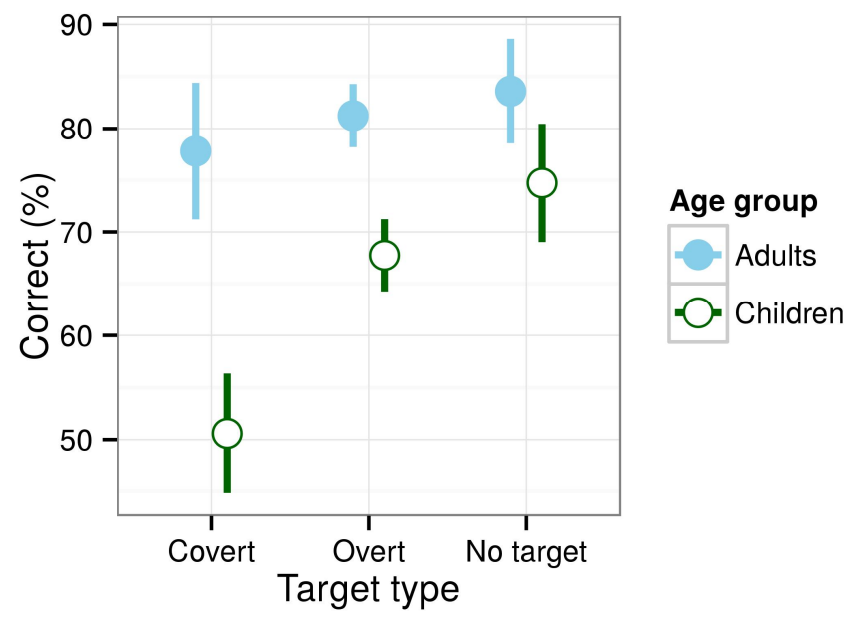

Figure 7. Mean percentages of correctly selected covert and overt targets in the SA tests, and the mean percentage of correct rejections for no target rectangles. The error bars indicate 95 $\%$ confidence intervals. The adult group is denoted with filled blue circles and the child group with open green circles.

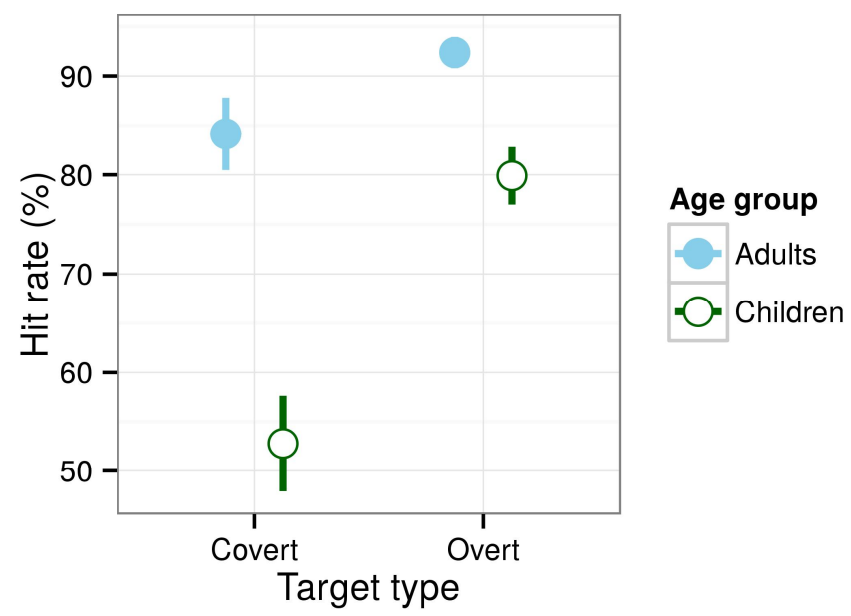

Figure 8. Mean hit rate for the learning game. The error bars indicate the $95 \%$ confidence interval. The adult group is denoted with filled blue circles and the child group with open green circles.

\subsection{Validity of the measures}

The criterion validity of the measures was investigated in two ways. First, we examined the convergent validity of the measures, that is, how well the measures correlated with each other in the expected manner. Second, we investigated the concurrent validity, that is, how possible it is to predict group membership based on the test scores. 
The correlations of the five measures are displayed in Table 4. Average over the three SA tests was used for the sensitivity and answer latencies. Sensitivity $d^{\prime}$ in the SA tests and hit rate in the game correlated in the expected way, but the time margin had a significant correlation only with the hit rate and the response bias $c$. Answer latency in the SA test was also weakly negatively correlated with hit rate and $d^{\prime}$.

Table 4. Pearson's correlations of the SA test and learning game measures. Significant $(p<.05)$ correlations were marked with *.

\begin{tabular}{|c|c|c|c|c|c|}
\hline & $d^{\prime}$ (Test) & $c$ (Test) & Answer latency (Test) & Hit rate (game) & Time margin (game) \\
\hline$d^{\prime}$ (Test) & 1 & $.50 *$ & $-0.24 *$ & $.43 *$ & .18 \\
\hline$c$ (Test) & $.50 *$ & 1 & -.18 & -.09 & $-.32 *$ \\
\hline Answer latency (Test) & $-.24 *$ & -.18 & 1 & $-.36 *$ & -.19 \\
\hline Hit rate (Game) & $.43 *$ & -.09 & $-.36 *$ & 1 & $.83 *$ \\
\hline Time margin (Game) & .18 & $-.32 *$ & -.19 & $.83 *$ & 1 \\
\hline
\end{tabular}

Predictability of the group membership was assessed with series of logistic regressions. Function multinom from R packages nnet was used to fit models (Venables \& Ripley, 2002). Percentage of correctly predicted participants for different models was calculated using the leave-one-out method: each participant's group membership was predicted using a model based on all other participants.

Prediction percentages for different models are presented in Table 5. Answer latency and response bias were not good predictors, because they perform even worse than predicting each participant to be a child $(49 / 80=61 \%)$. Combining the two best predictors produces a good prediction (Table 5 and Figure 9).

Table 5. Percentages of correctly predicted group memberships (children or adult) for different models.

$\begin{array}{ll}\text { Predictors in the model } & \text { Correctly predicted (\%) } \\ & \\ d^{\prime} \text { (Test) } & 81 \% \\ c \text { (Test) } & 58 \% \\ \text { Answer latency (Test) } & 60 \% \\ \text { Hit rate (Game) } & 88 \% \\ \text { Time margin (Game) } & 76 \% \\ d^{\prime}+\text { Hit rate } & 91 \% \\ d^{\prime}+\text { Hit rate + Interaction } & 89 \%\end{array}$




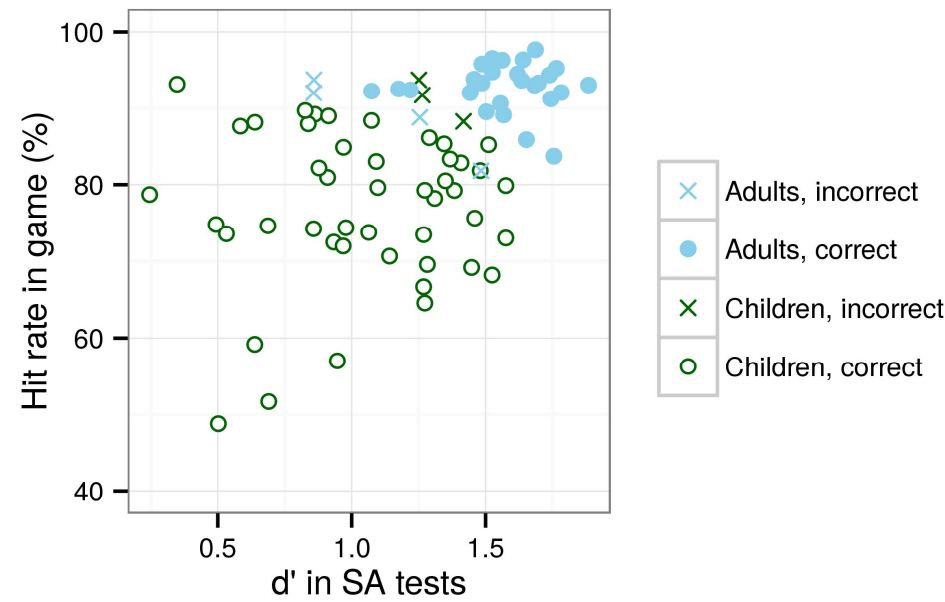

Figure 9. Hit rate (\%) in the learning game as a function of sensitivity $d$ ' over the three SA tests. Adults denoted as blue and children with green. The participants who were correctly predicted with a model including both the main effects $d^{\prime}$ and hit rate are marked with circles, and incorrectly predicted with crosses.

\subsection{Children's feedback of the game}

Forty-four out of 49 children reported that the game was 'fun' or 'very fun'. Four reported that the game was 'boring', none that is was 'very boring'. One answered, 'do not know'. 36 out of 49 children reported that the game was 'easy' or 'very easy'. 12 reported that the game was 'difficult' and none that it was 'very difficult'. One participant answered, 'do not know'. 39 out of 49 reported that they would play the game at home, seven were unsure and three said that they would not play the game at home. 


\section{DISCUSSION}

Children are a vulnerable group in traffic due to their still developing physical and cognitive abilities and their lack of experience (Barton and Morrongiello, 2011; Dye and Bavelier, 2010; Klenberg et al., 2001; Stewart et al., 2012). This is reflected in their less developed hazard perception skills (Meyer et al., 2014; Oron-Gilad et al., 2011). We assume that children's situational awareness could be trained with a computer based learning game, which should also improve their ability to anticipate/perceive hazardous situations. For this purpose we developed a learning game that could teach children better situation awareness (SA) in traffic in a safe environment. We also created a test for the assessment of situation awareness. Using a crossover/switching replications design we investigated whether the learning game improved SA.

Playing the learning game between the SA tests did not significantly increase sensitivity to targets, but the game did shorten the answer latencies and the response bias became marginally less conservative. Because the shortened answer latency was not accompanied with a decreased sensitivity, it could be interpreted that playing the learning game sped up the acquisition of situational awareness. This would be a positive effect because time is limited in traffic.

On the other hand, the game may have only cued the participants to respond fast, and to compensate for it, the participants may have used less conservative response criterion. However, because the participants were consistently too conservative in their responses (favored no target responses), this can be also seen as adaptive. In traffic, it is better to have a false alarm of a hazard than to leave a hazard unnoticed.

The SA test and the learning game consisted of videos of a similar type. It is possible that playing the game itself would not be required for changes in answer latency or response bias, but mere exposure to the video material would have been sufficient. In that case, the only value of the game would be to keep up the learner's motivation.

There was a significant difference between children and adults in the performance measures. As expected, the children had a lower sensitivity to targets and higher answer latencies in the SA tests compared with adults. In the learning game, adults had a higher hit rate and longer time margins to the last possible hit point. In other words, adults correctly identified more targets and were able to react to them faster than children. These results are in line with recent studies, which have found that children's HP skills are not as developed as adults' (e.g. Oron-Gilad et al., 2011; Meyer et al., 2014; Meir et al. 2015) and the cognitive skills required in the acquisition of situation awareness are not at the same level in children and adults (Barton and Morrongiello, 2011; Dye and Bavelier, 2010; Klenberg et al., 2001).

The performances was also studied as a function of target types. Whereas children were almost as good as adults at finding more overt targets such as visible cars, bicyclists and pedestrians in the SA tests, children performed much worse on finding covert targets. Adults were able to identify over $3 / 4$ of covert targets, whereas children only identified about half. Our results are in line with the findings of Meyer et al. (2014), Glad and Midtland (2000), and Meir et al. (2015) which suggest that children have more difficulty understanding that occlusions present potential dangers in traffic. This result can, however, partly be due to the fact that in spite of instructions in the tutorial videos and in practice clips, children did not properly understand the concept of these targets. Nevertheless, it should be noted that if the children had problems understanding the concept of covert targets in the context of the game and the tests, they will likely also have these problems in real traffic. 
Because both the SA tests and the learning game were novel, we investigate the criterion validity of the measures used. Sensitivity in the SA tests and the hit rate in the learning game were positively correlated with each other and could be satisfactorily used to predict group membership. This suggests that these measure the same underlying construct, which can be called SA.

The answer latency correlated negatively with sensitivity and with hit rate in the game. Time margin in the game was positively correlated with the hit rate, but not significantly correlated with sensitivity nor the answer latency in the SA tests. It should be noted that in the SA tests, participants were not asked to answer as quickly as possible, and they were not given any feedback on their answer speed. It is possible that participants used different strategies, some using more time for deliberately considering the alternatives and others basing their decision on their gut feeling. On the other hand, the self-paced nature of the task probes how fast the participants were able to form an answer they were satisfied with.

Even though the measures differentiated between children and adults, there was no consistent difference between infrequent and frequent adult cyclists as we expected based on our previous study (Lehtonen et al., 2015). However, it could be that the frequent cyclists were not experienced enough compared with the infrequent ones.

Based on the current results, it is not yet possible to distinguish whether the main difference between adults and children is due to the level of cognitive skills or to the level of experience. Especially, children have poorer working memory and executive functions than adults (Barton \& Morrongiello, 2011; Klenberg et al., 2001). Among experts, it has been found that measures of SA are fairly independent of measures of working memory (Endsley, 1995b), possibly because experienced persons are able to circumvent the working memory capacity limitations by employing long-term working memory (Durso \& Gronlund, 1999). Among novices, who children most often are, the limited working memory capacity is probably more important for performance.

It is even possible that the SA test itself burdens the children's working memory too much, biasing the results. This is an important point to consider. However, we are inclined to think that the cognitively demanding part of the SA test was not asking participants to maintain the information during answering, but to create a strong enough memory representation of the elements while watching the video which would be important for SA in real traffic. Sensitivity in the SA tests was also positively correlated with hit rate in the learning game, where it was not required to maintain information in working memory during answering.

\subsection{Conclusion}

Based on the current results, it is not yet possible to conclude that the learning game would be an effective way to teach situation awareness/hazard perception for child bicyclists. The situation awareness tests were able to capture the expected difference between children and young adults. Non-obvious, covert targets (occlusions) were especially challenging for children.

Further studies are needed for exploring the potential of the learning games aimed for improving child bicyclists' traffic safety. First, it would be necessary to investigate more long term exposure to the learning game, as a main limitation of the current study is the short playing time (20 min). It is possible that this was too short for demonstrating an improvement in sensitivity. Second, the current version of the game was a point-and-shoot type of game. Even though fast paced video games may improve attentional skills (e.g. Green \& Bavelier, 2012) and thus help in the acquisition of situation awareness, it is possible that children would benefit more from training which requires more 'thinking'. According to cognitive 
load theory, learners learn cognitive skills best when they need to use their working memory to solve problems, but it is necessary for the problems to be adapted so that their working memory does not become overburdened (Kirschner et al., 2006; Paas et al., 2010).

It is important to remember that educational interventions like learning games are only a remedy, not a cure. Children's traffic safety is not primarily endangered by the children themselves, but by adults, who are responsible for operating motorized vehicles in a safe manner and for designing the traffic environment so that it would be safe for children.

\section{Acknowledgements}

Several people greatly helped in the making of this study. Marko Tikka filmed the video footage. Perttu Lähteenlahti contributed to the programming of the learning game. Leena-Johanna Huotarinen-Ahonen, Pinja Marin, Marianne Melin, Jonna Peltonen, Jade Plym, Liisa Polet, Lia Sandell and Anna Vuorela collected the children's data and participated in the creation of the study. The two schools and their pupils and personnel receive the greatest thanks. To keep their anonymity, we do not disclose any names. Caitlin Dawson proofread the revised manuscript. The study received funding from the Finnish Transport Safety Agency Trafi. 


\section{REFERENCES}

P. Ahopalo, A. Lehikoinen and H. Summala. "Kuljettajan ajokokemus ja vaaratilanteiden havaitseminen" ("Driving experience and response latencies in hazard perception"), Reports of Traffic Research Unit 12 (1987). Helsinki: University of Helsinki.

B. K. Barton and B. A. Morrongiello, "Examining the impact of traffic environment and executive functioning on children's pedestrian behaviors", Developmental Psychology 47(1) (2011), pp. 182.

A. Borowsky, T. Oron-Gilad and Y. Parmet, "Age and skill differences in classifying hazardous traffic scenes", Transportation Research Part F: Traffic Psychology and Behaviour 12(4) (2009), pp. 277-287.

A. Borowsky, \& T. Oron-Gilad, Exploring the effects of driving experience on hazard awareness and risk perception via real-time hazard identification, hazard classification, and rating tasks. Accident Analysis \& Prevention, 59 (2013), 548-565.

P. Chapman, G. Underwood \& K. Roberts, "Visual search patterns in trained and untrained novice drivers", Transportation Research Part F: Traffic Psychology and Behaviour 5(2) (2002), 157-167.

B. J. Chihak, J. M. Plumert, C. J. Ziemer, S. Babu, T. Grechkin, J. F. Cremer \& J. K. Kearney, "Synchronizing self and object movement: how child and adult cyclists intercept moving gaps in a virtual environment", Journal of Experimental Psychology: Human Perception and Performance 36(6) (2010), $1535-1552$.

T. M. Connolly, E. A. Boyle, E. Macarthur, T. Hainey, \& J. M. Boyle, "A systematic literature review of empirical evidence on computer games and serious games", Computers \& Education, 59(2) (2012), 661686.

D. Crundall. Hazard prediction discriminates between novice and experienced drivers. Accident Analysis \& Prevention, 86 (2016), 47-58.

D. Crundall, G. Underwood and P. Chapman, "Attending to the peripheral world while driving", Applied Cognitive Psychology 16(4) (2002), 459-475.

D. Crundall, P. Chapman, S. Trawley, L. Collins, E. Van Loon, B Andrews, \& G. Underwood, "Some hazards are more attractive than others: Drivers of varying experience respond differently to different types of hazard", Accident Analysis \& Prevention 45 (2012), pp. 600-609.

J. J. De Hartog, H. Boogaard, H. Nijland and G. Hoek, "Do the health benefits of cycling outweigh the risks?", Environmental Health Perspectives (2010), 1109-1116.

G. Dunbar, R. Hill and V. Lewis, "Children's attentional skills and road behavior", Journal of Experimental Psychology: Applied 7(3) (2001), 227-234.

F. T. Durso and S. D. Gronlund, "Situation awareness" in F. T. Durso Ed. (1999) Handbook of Applied Cognition. Wiley, New York, 283-314.

M. W. G. Dye and D. Bavelier, "Differential development of visual attention skills in school-age children", Vision Research 50 (2010), 452-259. 
J. Ellis, Bicycle safety education for children from a developmental and learning perspective (Report No. DOT HS 811 880). A Literature Review for NHTSA Through the National Safety Council (2014). Washington, DC: National Highway Traffic Safety Administration.

M. R., Endsley, "Toward a theory of situation awareness in dynamic systems", Human Factors: The Journal of the Human Factors and Ergonomics Society 37(1) (1995a), 32-64.

M. R. Endsley, "Measurement of situation awareness in dynamic systems", Human Factors 37(1) (1995b), 65-84.

C. Girard, J. Ecalle, \& A. Magnan, (2013). Serious games as new educational tools: How effective are they? A meta-analysis of recent studies. Journal of Computer Assisted Learning, 29(3), 207-219.

A. Glad and K. Midtland, "Six Years Old Children and Crossing of Roads. Results of a training experiment", Nordic Road and Transport Research 2 (2000).

C. S. Green \& D. Bavelier, "Learning, attentional control, and action video games", Current Biology 22(6) (2012), R197-R206.

D. M. Green, \& J. A. Swets, (1966) Signal detection theory and psychophysics. Wiley, New York.

T. Y. Grechkin, B. J. Chihak, J. F. Cremer, J. K. Kearney and J. M. Plumert, "Perceiving and acting on complex affordances: How children and adults bicycle across two lanes of opposing traffic", Journal of Experimental Psychology: Human Perception and Performance 39(1) (2013), 23-36.

R. Hill, V. Lewis \& G. Dunbar, "Young children's concepts of danger", British Journal of Developmental Psychology 18(1) (2000), 103-119.

M. S. Horswill and F. P. McKenna, "Drivers' hazard perception ability: Situation awareness on the road", in A Cognitive Approach to Situation Awareness, S. Banbury and S. Tremblay, pp. 155-175. UK: Ashgate, 2004.

M. S. Horswill, A. Hill and M. Wetton, "Can a video-based hazard perception test used for driver licensing predict crash involvement?", Accident Analysis \& Prevention 82 (2015), 213-219.

S. G. Hosking, C. C. Liu \& M. Bayly, "The visual search patterns and hazard responses of experienced and inexperienced motorcycle riders", Accident Analysis \& Prevention 42(1) (2010), 196-202.

L. Jackson, P. Chapman \& D. Crundall, "What happens next? Predicting other road users' behaviour as a function of driving experience and processing time", Ergonomics 52(2) (2009), 154-164.

P. A.. Kirschner, J. Sweller, J., \& R. E. Clark, "Why Minimal Guidance During Instruction Does Not Work: An Analysis of the Failure of Constructivist, Discovery, Problem-Based, Experiential, and InquiryBased Teaching". Educational Psychologist, 41(2) (2006), 75-86.

L. Klenberg, M. Korkman \& P. Lahti-Nuuttila, "Differential Development of Attention and Executive Functions in 3- to 12-Year-Old Finnish Children", Developmental Neuropsychology 20(1) (2001), 407428.

M. A. Lawrence (2015). ez: Easy Analysis and Visualization of Factorial Experiments. R package version 4.3. http://CRAN.R-project.org/package $=\mathrm{ez}$ 
E. Lehtonen, O. Lappi, I. Koirikivi \& H. Summala, "Effect of driving experience on anticipatory lookahead fixations in real curve driving", Accident Analysis and Prevention 70 (2014), 195-208.

E. Lehtonen, V. Havia, A. Kovanen, M. Leminen \& E. Saure, "Evaluating bicyclists' risk perception using video clips: Comparison of frequent and infrequent city cyclists", Transportation Research Part F: Traffic Psychology and Behaviour 41 Part B (2016), 195-203.

Liikenneturva - Finnish Road Safety Council, Alakouluikäisten lasten henkilövahingot tieliikenteessä. Tilastokatsaus (2015a). (Injuries and fatalities in traffic involving children aged 7-12. Statistical review.) https://www.liikenneturva.fi/sites/default/files/materiaalit/Tutkittua/Tilastot/tilastokatsaukset/tilastokatsau s_alakouluikaiset.pdf

Liikenneturva - Finnish Road Safety Council, Pyöräilijöiden henkilövahingot tieliikenteessä. Tilastokatsaus (2015b). (Bicyclists' injuries and fatalities in road traffic. Statistical review.) https://www.liikenneturva.fi/sites/default/files/materiaalit/Tutkittua/Tilastot/tilastokatsaukset/tilastokatsau s_pyorailijat.pdf

C. Macarthur, P. C. Parkin, M. Sidky \& W. Wallace, "Evaluation of a bicycle skills training program for young children: a randomized controlled trial", Injury Prevention, 4(2) (1998), 116-121.

C. C. McDonald, A. H. Goodwin, A. K. Pradhan, M. R. E. Romoser and A. F. Williams, "A Review of Hazard Anticipation Training Programs for Young Drivers", Journal of Adolescent Health 57(1 Supplement) (2015), S15-S23

F. P. McKenna and J. L. Crick, "Hazard perception in drivers: A methodology for testing and training", TRL Contractor Report (313) (1994).

K. McLaughlin and A. Glang, "The effectiveness of a bicycle safety program for improving safety-related knowledge and behavior in young elementary students", Journal of Pediatric Psychology 35 (2010), 343353.

A. Meir, Y. Parmet and T. Oron-Gilad, "Towards understanding child-pedestrians' hazard perception abilities in a mixed reality dynamic environment", Transportation research part F: traffic psychology and behaviour 20, (2013), 90-107.

A. Meir, T. Oron-Gilad, \& Y. Parmet. Can child-pedestrians' hazard perception skills be enhanced? Accident Analysis \& Prevention, 83 (2015), 101-110.

S. Meyer, F. Sagberg and R. Torquato, "Traffic hazard perception among children", Transportation Research Part F: Traffic Psychology and Behaviour 26 (2014), 190-198.

T. Oron-Gilad, A. Meir, H. Tapiro and A. Borowsky, Towards understanding child-pedestrian's deficits in perceiving hazards when crossing the road, final report, Negev: Ben-Gurion University, Human Factors Engineering Laboratory, 2011.

〈http://www.rannaorf.org.il/webfiles/files/Child_pedestrians_HP_abilities.pdf〉.

D. C. Pelz, and E. Krupat, "Caution profile and driving record of undergraduate males", Accident Analysis \& Prevention 6(1) (1974), 45-58. 
F. Paas, van T. Gog, \& J. Sweller, "Cognitive Load Theory: New Conceptualizations, Specifications, and Integrated Research Perspectives”, Educational Psychology Review (2010), 115-121.

J. M. Plumert, J. K. Kearney and J. F. Cremer, "Children's Perception of Gap Affordances: Bicycling Across Traffic-Filled Intersections in an Immersive Virtual Environment", Child Development 75(4) (2004), 1243-1253.

J. M. Plumert, J. K. Kearney, J. F. Cremer, K. M. Recker and J. Strutt, "Changes in children's perceptionaction tuning over short time scales: Bicycling across traffic-filled intersections in a virtual environment", Journal of Experimental Child Psychology 108(2) (2011), pp. 322-337.

A. K., Pradhan, A. Pollatsek, M. Knodler, \& D. L. Fisher, "Can younger drivers be trained to scan for information that will reduce their risk in roadway traffic scenarios that are hard to identify as hazardous?" Ergonomics, 52(6) (2009), 657-673.

S. A. Richmond, Y. J. Zhang, A. Stover, A. Howard and C. Macarthur, "Prevention of bicycle-related injuries in children and youth: a systematic review of bicycle skills training interventions", Injury Prevention 20 (2014), 191-195.

L. Russell (2015). lsmeans: Least-Squares Means. R package version 2.20-2. http://CRAN.R-project.org/package=lsmeans

F. Sagberg \& T. Bjørnskau, "Hazard perception and driving experience among novice drivers", Accident Analysis \& Prevention 38(2) (2006), pp. 407-414.

S. Schaefer, R. T. Krampe, U. Lindenberger \& P. B. Baltes, "Age differences between children and young adults in the dynamics of dual-task prioritization: Body (balance) versus mind (memory)", Developmental Psychology 44(3) (2008), 747-757.

H. Stanislaw \& N. Todorov, "Calculation of signal detection theory measures", Behavior Research Methods, Instruments, \& Computers, 31(1) (1999), 137-149.

O. Stewart, A. V. Moudon and C. Claybrooke, "Common ground: eight factors that influence walking and biking to school", Transport Policy 24 (2012), pp. 240-248.

D. C. Thompson, R. S. Thompson and F. P. Rivara, "Incidence of Bicycle-Related Injuries in a Defined Population", American Journal of Public Health 80(11) (1990), 1388-1390.

G. Underwood, N. Phelps, C. Wright, E. Van Loon, A. Galpin, "Eye fixation scanpaths of younger and older drivers in a hazard perception task", Ophthalmic and Physiological Optics 25(4), (2005), 346-356.

G. Underwood, "Visual attention and the transition from novice to advanced driver", Ergonomics 50(8), (2007), 1235-1249.

G. Underwood, A. Ngai and J. Underwood, "Driving experience and situation awareness in hazard detection", Safety Science 56 (2013), 29-35.

W. N. Venables, W. N. \& B. D. Ripley, B. D. (2002) Modern Applied Statistics with S. Fourth edition. Springer. 
P. Ventsislavova, A. Gugliotta, E. Peña-Suarez, P. Garcia-Fernandez, E. Eisman, D. Crundall, \& C. Castro, "What happens when drivers face hazards on the road?" Accident Analysis and Prevention 91 (2016), 43-54.

Vlakveld, W. P., A comparative study of two desktop hazard perception tasks suitable for mass testing in which scores are not based on response latencies. Transportation Research Part F: Traffic Psychology and Behaviour 22, (2014), 218-231.

C. D. Wickens, "Situation awareness: Review of Mica Endsley's 1995 articles on situation awareness theory and measurement", Human Factors: The Journal of the Human Factors and Ergonomics Society 50(3) (2008), 397-403. 